\title{
Biofuels Subsidies and the Green Paradox
}

\author{
R. Quentin Grafton \\ Tom Kompas \\ Ngo Van Long
}

\author{
CESIFO WORKING PAPER NO. 2960 \\ CATEgORY 10: ENERGY AND ClimATE ECONOMICS \\ FEBRUARY 2010
}
An electronic version of the paper may be downloaded
- from the SSRN website: Www.SSRN.com
- from the RePEc website: Www.RePEc.org
- from the CESifo website: www.CESifo-group.org/wp




\title{
Biofuels Subsidies and the Green Paradox
}

\begin{abstract}
This paper develops sufficient conditions under which the Weak Green Paradox may (and may not) hold in terms of subsidies for biofuel production such that the supply-side responses by fossil fuel producers may more than offset the substitution to biofuels. Analytical results are derived and numerical simulations show that, under a wide range of parameter values, biofuel subsidies will increase the rate of extraction of fossil fuels in the short and medium term, and possibly bring climate-change damages closer to the present.
\end{abstract}

JEL-Code: Q54, Q42, Q30.

Keywords: biofuels subsidies, the Green Paradox.

\author{
R. Quentin Grafton \\ Crawford School \\ Australian National University \\ quentin.grafton@ana.edu.au
}

\author{
Tom Kompas \\ Crawford School \\ Australian National University \\ tom.kompas@ana.edu.au
}

\footnotetext{
Ngo Van Long

McGill University

ngo.long@mcgill.ca
}

This Version: 19 February 2010 


\section{Introduction}

Biofuels are widely regarded as a means to reduce greenhouse gas (GHG) emissions because they have the potential, relative to the fossil fuels they replace, to reduce GHG emissions. Consequently, biofuel subsidies have been promoted because of their potential environmental benefits (Hill et al. 2006). In 2006, in selected OECD countries, the total level of government support for biofuels exceeded $\$ 10$ billion (Steenblik, 2007). This is despite the fact that, one, a first-best instrument to control GHG emissions would be to establish a carbon tax or an equivalent cap-and-trade scheme and, two, biofuels production is blamed for some of the recent increases in prices of a number of food staples (FAO 2008).

Until very recently the supply-side dynamics of biofuel subsidies and their effects on inter-temporal extraction of fossil fuels have been ignored. The presumption has been that by increasing the supply of a readily-available substitute this would lower the price of fossil fuels, thereby lowering the incentive to extract. ${ }^{1}$ However, if fossil fuel resource owners optimally extract their reserves and expect on-going or increased subsidies for biofuel production then they may increase their current levels of extraction. ${ }^{2}$ It is even possible that this supply-side effect may overwhelm the substitution effect from fossil fuels to biofuels and increase GHG emissions leading to a Green Paradox (Sinn, 2008b). However, this would depend, among other factors, on the direct reduction in GHG emissions that arises from biofuel-fossil fuel substitution. ${ }^{3}$

\footnotetext{
${ }^{1} \mathrm{~A}$ secondary argument is that with increased production of biofuels, technological progress will lower costs of production due to learning by doing.

${ }^{2}$ This is similar to the insights of Long and Sinn (1985) who investigate how extractive firms respond to anticipation of future tax changes.

${ }^{3}$ The extent to which direct biofuel-fossil fuel substitution reduces GHG emissions is a matter of some debate. An authoritative study on this issue indicates that with direct substitution there would be a reduction in GHG emissions of $12 \%$ for ethanol and $41 \%$ for biodiesel (Hill et al. 2006).
} 
The possibility that adverse supply side effects may arise has been identified by Sinn (2008a) in the case of carbon taxes. Sinn's view is supported by Hoel (2008) using a model of investment in a backstop technology, and extends earlier work on the optimal trend of fossil fuel taxation (Sinclair 1992, Ulph and Ulph 1994). We show that this line of argument is equally valid in the context of biofuels subsidies. In other words, policies designed to reduce GHG emissions by subsidizing biofuel production may increase fossil fuel production. We define such an outcome as a Weak Green Paradox. In turn, increased fossil fuel consumption may raise atmospheric GHG concentration levels that would depend on many factors such as future technological change that may affect extraction costs, the reductions in GHG emissions from biofuel-fossil fuel direct substitution, and the effects of GHG concentration levels on the rate of carbon decay in the atmostphere. We define this second outcome as a Strict Green Paradox.

In this paper we develop formal models to study the conditions under which the Weak Green Paradox would (or would not) hold in the context of the direct subsidization biofuels production (such as in the US) or quantitative regulations that ensure minimum levels of biofuel consumption (such as in the EU). The analysis focuses on the supply response of fossil fuel producers, and the resulting general equilibrium changes in price paths and quantity paths.

In the simplest case where the supply curve of biofuels is upward sloping, and where biofuels are a perfect substitute for fossil fuels, at any given price of energy a subsidy on biofuel production will shift the biofuel supply curve to the right, resulting in a lower demand for fossil fuels. However, the equilibrium price path of energy is not given, because suppliers of fossil fuels will react to the biofuel subsidies. Thus, as soon as a credible time path in terms of the subsidy rate is announced or deduced, fossil fuel producers should adjust their output paths. Depending on supply and demand elasticities, this 
may induce increased fossil fuel production.

We first investigate the possible effects of biofuel subsidies on the time path of fossil fuel extraction. ${ }^{4}$ In this approach, consumption of fossil fuels is equal to extraction from an aggregate stock of fossil-fuel resource, $\bar{R}$. If biofuel subsidies have the effect of hastening the exhaustion of the stock $\bar{R}$ (i.e., shifting extraction of fossil fuels to the present), this allows for the possibility of a Weak Green Paradox which arises when fossil fuel production more than offsets the direct substitution to biofuels. We examine separately the cases of linear and non-linear demand, and extraction costs that depend on the remaining reserves.

In addition to analytical results, we provide numerical simulations of the effects on fossil fuel production from biofuels subsidies under a range of parameter values. We also present a set of sufficient conditions for fossil fuel production to increase in the presence of biofuel subsidies, and sufficient conditions when it fails to hold. Overall, our findings indicate that biofuel subsidies could increase fossil fuel production in the foreseeable future and, thus, result in a Weak Green Paradox.

\section{Weak Green Paradox: competitive extrac- tion}

This section presents a model of energy demand in a perfectly competitive world, and shows that increased fossil fuel production can more than offset substitution to biofuels due to subsidies for biofuel production.

In our model, there are two consumption goods: a numeraire good (leisure) and a manufactured good. The latter good uses fuels as an input. The demand for the manufactured good gives rise to the demand for fuels. Assume

\footnotetext{
${ }^{4}$ There are a number of studies of biofuel subsidies (e.g. Chakravorty et al., 2009, Bahel Marrouch, 2009) and but they do not focus on the effect of subsidies on the date of exhaustion of the fossil-fuel stock.
} 
there are two types of fuels: fossil fuels and biofuels. For simplicity, we assume they are perfect substitutes.

Let $P_{t}$ denote the market price of fuels at time $t$. The present moment is $t=0$. Assume that the world economy's demand for fuels is

$$
E_{t}^{d}=D\left(P_{t}\right)
$$

where $D^{\prime}()<$.0 .

Assume that biofuel producers receive a constant ad valorem subsidy rate $\theta \geq 0$, i.e. for each unit they sell, they receive $(1+\theta) P_{t}$. Let $z \equiv 1+\theta \geq 1$. We call $z$ the "subsidy factor", where $z=1$ indicates that the subsidy rate is zero. Let $B_{t}$ denote the quantity of biofuels supplied. The supply function of biofuels is

$$
B_{t}=S_{B}\left(z P_{t}\right)
$$

where we assume $S_{B}^{\prime}>0$ and $S_{B}(0)=g \geq 0$.

At time $t=0$, there is a fixed aggregate stock of fossil fuels, $\bar{R}$. The suppliers of fossil fuels are far-sighted and perfectly competitive extractive firms. They perfectly forecast the equilibrium price path $P(t)$ which they take as given. We assume that the marginal cost of extraction is a constant $c \geq 0$. If extraction rates are strictly positive over some time interval $[0, T]$ then, by Hotelling's Rule, ${ }^{5}$ the "net price" (i.e. price minus extraction cost) $P_{t}-c$ must rise at a rate equal to the rate of interest, i.e.

$$
\frac{\dot{P}_{t}}{P_{t}-c}=r \text { for } t \in[0, T] .
$$

The demand for fossil fuels is defined as the difference between the demand for fuels and the supply of biofuels:

$$
D_{f}(P ; z) \equiv D(P)-S_{B}(z P)
$$

\footnotetext{
${ }^{5}$ See Gaudet (2007) for a survey of theoretical and empirical studies on Hotelling's Rule.
} 
We call $D_{f}(P ; z)$ the residual demand function. Given $z$, there is a unique price $\bar{P}$ such that the supply of biofuels just matches the demand for fuels. The price $\bar{P}$ is implicitly defined by

$$
D(\bar{P})-S_{B}(z \bar{P})=0
$$

Clearly, $P(t)$ cannot rise above $\bar{P}$. We call $\bar{P}$ "the choke price for fossil fuels". Notice that $\bar{P}$ depends on the subsidy factor $z$. A higher $z$ implies a lower $\bar{P}$. For ease of reference, we state this result as Fact 1:

Fact 1: $\bar{P}=\bar{P}(z)$ and its derivative is given by

$$
\frac{d \bar{P}}{d z}=-\frac{\frac{\partial D_{f}(\bar{P}, ; z)}{\partial z}}{\frac{\partial D_{f}(\bar{P}, ; z)}{\partial P}}=\frac{\bar{P} S_{B}^{\prime}(z \bar{P})}{D^{\prime}(\bar{P})-z S_{B}^{\prime}(z \bar{P})}<0
$$

Market equilibrium requires that the stock of fossil fuels be exhausted exactly at the (endogenously determined) time $T$ when $P$ reaches $\bar{P}$.We will show below how the exhaustion date $T$ and the initial price $P_{0}$ depend on the subsidy factor $z$. In what follows, we assume that $\bar{P}>c$. By definition, the price of fuels at the exhaustion time $T$ is equal to the the choke price for fossil fuels, $\bar{P}$ :

$$
P_{T}=\bar{P}
$$

From Hotelling's Rule, the present value of the net price is the same for all $t \in[0, T]:$

$$
\left(P_{t}-c\right) e^{-r t}=(\bar{P}-c) e^{-r T} \text { for all } t \leq T
$$

i.e., for all $t \leq T$,

$$
P_{t}=c+(\bar{P}-c) e^{r(t-T)}=c+[\bar{P}(z)-c] e^{r(t-T)} \equiv \phi(\bar{P}(z), t, T)
$$

Note that the function $\phi(\bar{P}(z), t, T)$ has the following properties:

$$
\frac{\partial \phi(\bar{P}(z), t, T)}{\partial T}=-r[\bar{P}(z)-c] e^{r(t-T)}=-r\left(P_{t}-c\right)<0
$$


and

$$
\frac{\partial \phi(\bar{P}, t, T)}{\partial \bar{P}}=e^{r(t-T)}>0
$$

To determine $T$, we use the equilibrium condition that total demand for fossil fuels over the time interval $[0, T]$ is exactly equal to the initial stock $\bar{R}$ :

$$
\int_{0}^{T} D_{f}\left(P_{t} ; z\right) d t=\bar{R}
$$

where $P_{t}$ is given by eq $(5)$. In other words, the following equation uniquely determines the resource-exhaustion date $T$ :

$$
\int_{0}^{T} D_{f}(\phi(\bar{P}(z), t, T) ; z) d t=\bar{R}
$$

We seek the answer to the following question: does an increase in the subsidy factor $z$ bring the exhaustion time $T$ closer to the present? If the answer is "yes", then we say that the Weak Green Paradox is confirmed. As a first step, let us state a useful Lemma:

Lemma 1: An increase in the subsidy factor $z$ will bring the resourceexhaustion date $T$ closer to the present if and only if

$$
\int_{0}^{T}\left[\frac{\partial D_{f}}{\partial P_{t}} \frac{\partial \phi}{\partial \bar{P}} \frac{d \bar{P}}{d z}+\frac{\partial D_{f}}{\partial z}\right] d t>0
$$

Proof: Let

$$
G(T, z, \bar{R}) \equiv \int_{0}^{T} D_{f}(\phi(\bar{P}(z), t, T) ; z) d t-\bar{R}
$$

The equilibrium condition that the stock of resources is exhausted at time $T$, i.e. $G(T, z, \bar{R})=0$, implicitly determines $T$ as a function of $z$. The derivative $d T / d z$ is given by

$$
\frac{d T}{d z}=-\frac{\frac{\partial G(T, z, \bar{R})}{\partial z}}{\frac{\partial G(T, z, \bar{R})}{\partial T}}
$$

where

$$
\frac{\partial G(T, z ; \bar{R})}{\partial T}=D_{f}(\phi(\bar{P}(z), T, T) ; z)+\int_{0}^{T} \frac{\partial D_{f}}{\partial \phi} \frac{\partial \phi}{\partial T} d t>0
$$


and

$$
\frac{\partial G(T, z ; \bar{R})}{\partial z}=\int_{0}^{T}\left[\frac{\partial D_{f}}{\partial P_{t}} \frac{\partial \phi}{\partial \bar{P}} \frac{d \bar{P}}{d z}+\frac{\partial D_{f}}{\partial z}\right] d t
$$

In general, the sign of the right-hand side of equation (14) is uncertain. Let us consider a few special cases.

\subsection{Weak Green Orthodox: linear demand}

Let us consider the special case where the fuel demand function $D($.$) is linear,$

$$
D(p)=a-b P, \quad a>0, b>0
$$

and the biofuel supply function is

$$
S_{B}(z P)=g+\beta(z P)^{\mu}, \quad \beta>0, \mu>0
$$

where $g$ is a constant. Then the demand function for fossil fuels is

$$
D_{f}(P ; z) \equiv a-b P-g-\beta(z P)^{\mu}
$$

The "fossil fuel choke price" $\bar{P}(z)$ is implicitly defined by

$$
a-b \bar{P}-g-\beta(z \bar{P})^{\mu}=0
$$

Thus

$$
\frac{d \bar{P}}{d z}=-\frac{\mu \beta z^{\mu-1}(\bar{P})^{\mu}}{b+\mu \beta z^{\mu}(\bar{P})^{\mu-1}}<0
$$

The integrand in equation (10) is

$\frac{\partial D_{f}}{\partial p_{t}} \frac{\partial \phi}{\partial \bar{P}} \frac{d \bar{P}}{d z}+\frac{\partial D_{f}}{\partial z}=\left[b+\mu \beta z^{\mu}\left(P_{t}\right)^{\mu-1}\right] e^{r(t-T)} \frac{\mu \beta z^{\mu-1}(\bar{P})^{\mu}}{b+\mu \beta z^{\mu}(\bar{P})^{\mu-1}}-\mu \beta z^{\mu-1}\left(P_{t}\right)^{\mu}$

If $\mu=1$, this integrand expression reduces to

$$
\frac{\partial D_{f}}{\partial p_{t}} \frac{\partial \phi}{\partial \bar{P}} \frac{d \bar{P}}{d z}+\frac{\partial D_{f}}{\partial z}=\beta\left[\bar{P} e^{r(t-T)}-P_{t}\right]
$$


which is equal to

$$
-\beta c\left[1-e^{-r(T-t)}\right] \leq 0
$$

From Lemma 1 and equation (16), we can state a result that does not support the Weak Green Paradox:

Proposition 1: Assume that the demand function for fuels and the supply function of biofuels are both linear. Then under perfectly competitive extraction,

(i) if extraction costs are zero $(c=0)$, an increase in the biofuel subsidy factor $z$ will have no effect on the date of exhaustion of the resource stock $\bar{R}$;

(ii) if extraction costs are positive $(c>0)$, an increase in the biofuel subsidy factor $z$ will delay the date of exhaustion of the resource stock $\bar{R}$.

\subsection{Weak Green Paradox: non-linear demand}

An unattractive feature of the linear demand specification is that the demand for fuels becomes zero at some finite price. Many people would argue that the demand for fuels is always positive at any finite price. Let us consider the case where the demand for fuels is of the form

$$
E^{d}=(P+\delta)^{-\varepsilon} \equiv D(P)
$$

where $\delta \geq 0$ and $\varepsilon>0$.

The demand function (17) may be derived from the demand for the manufactured good. For example, suppose that to produce one unit of the manufactured good, one needs to use one unit of fuels and one unit of labor. Let $P$ be the price of fuels and $\delta$ be the wage rate. Assume perfect competition and constant returns to scale in the manufactured good industry. Then the price of the manufactured good is equal to its unit cost, which is the sum of $P$ and $\delta$ :

$$
P_{M}=P+\delta
$$


Assume the demand for the manufactured good is

$$
Q^{d}=\left(P_{M}\right)^{-\varepsilon} \equiv D_{M}\left(P_{M}\right)
$$

where $\varepsilon>0$ is the elasticity of demand for the manufactured good:

$$
\varepsilon=-\frac{P_{M}}{Q^{d}}\left(\frac{d Q^{d}}{d P_{M}}\right)>0
$$

By choice of units of measurement, $E^{d}=Q^{d}$. From this we obtain the fuel demand function (17). The elasticity of demand for fuels is denoted by $\eta$ where

$$
\eta \equiv-\frac{P}{E^{d}} \frac{d E^{d}}{d P}=-\frac{\left(P_{M}-\delta\right)}{Q^{d}}\left(\frac{d Q^{d}}{d P_{M}}\right)=\varepsilon+\frac{\delta}{Q^{d}} \frac{d Q^{d}}{d P_{M}}
$$

Therefore $\eta$ is smaller than or equal to $\varepsilon$, with equality holding only in the case where $\delta=0$.

We continue to assume that the supply function of biofuels is of the form

$$
S_{B}(z P)=g+\beta(z P)^{\mu}, \quad \beta>0, \mu>0, z>0
$$

Then the (residual) demand for fossil fuels is

$$
D_{f}(P ; z)=(P+\delta)^{-\varepsilon}-g-\beta(z P)^{\mu}
$$

and $\bar{P}$ satisfies

$$
(\bar{P}+\delta)^{-\varepsilon}-g-\beta(z \bar{P})^{\mu}=0
$$

From this, we get

$$
\frac{d \bar{P}}{d z}=-\frac{\beta \mu z^{\mu-1}(\bar{P})^{\mu}}{\varepsilon(\bar{P}+\delta)^{-\varepsilon-1}+\mu \beta z^{\mu}(\bar{P})^{\mu-1}}<0
$$

The integrand in equation (10) is

$$
I(\phi(\bar{P}(z), t, T) ; z) \equiv \frac{\partial D_{f}}{\partial p_{t}} \frac{\partial \phi}{\partial \bar{P}} \frac{d \bar{P}}{d z}+\frac{\partial D_{f}}{\partial z}=
$$




$$
e^{r(t-T)}\left[\frac{\beta \mu z^{\mu-1}(\bar{P})^{\mu}\left(\varepsilon\left(P_{t}+\delta\right)^{-\varepsilon-1}+\mu \beta z^{\mu}\left(P_{t}\right)^{\mu-1}\right)}{\varepsilon(\bar{P}+\delta)^{-\varepsilon-1}+\mu \beta z^{\mu}(\bar{P})^{\mu-1}}\right]-\beta \mu z^{\mu-1}\left(P_{t}\right)^{\mu}
$$

Let us formalize our result as follows:

Assumption A: The fuel demand function has the form (17) and the biofuel supply function has the form (19).

Proposition 2: Under Assumption A, an increase in the subsidy factor $z$ will bring the exhaustion date closer to the present if and only if

$$
\int_{0}^{T}\left\{e^{r(t-T)}\left[\frac{\beta \mu z^{\mu-1}(\bar{P})^{\mu}\left(\varepsilon\left(P_{t}+\delta\right)^{-\varepsilon-1}+\mu \beta z^{\mu}\left(P_{t}\right)^{\mu-1}\right)}{\varepsilon(\bar{P}+\delta)^{-\varepsilon-1}+\mu \beta z^{\mu}(\bar{P})^{\mu-1}}\right]-\beta \mu z^{\mu-1}\left(P_{t}\right)^{\mu}\right\} d t>0
$$

i.e.

$$
\beta \mu z^{\mu-1}(\bar{P})^{\mu} \int_{0}^{T}\left\{e^{r(t-T)}\left[\frac{\varepsilon\left(P_{t}+\delta\right)^{-\varepsilon-1}+\mu \beta z^{\mu}\left(P_{t}\right)^{\mu-1}}{\varepsilon(\bar{P}+\delta)^{-\varepsilon-1}+\mu \beta z^{\mu}(\bar{P})^{\mu-1}}\right]-\left(\frac{P_{t}}{\bar{P}}\right)^{\mu}\right\} d t>0
$$

This condition is satisfied under plausible specifications of parameter values.

\section{Numerical examples}

In our base-line scenario, the parameters are:

$$
\varepsilon=\delta=\beta=\mu=1, \quad r=0.05, \quad c=g=0
$$

Let the reserve size $\bar{R}$ be large enough so that under this base-line scenario, the exhaustion time is $T=100$ years.

Then we find that, starting at the initial subsidy factor $z=1$, an increase in $z$ leads to an earlier exhaustion time, that is,

$$
\frac{d T}{d z}=-2.09
$$

This shows that the Weak Green Paradox holds if the reserve size is such that $T=100$. Is this result sensitive to the size of the reserve? Let us vary the reserve size so that $T$ varies from 50 years to 200 years. We find that $d T / d z$ remains negative, and not far different from -2.09 . Table 1 below reports the value $d T / d z$ for various reserve sizes (and hence various $T$ ). 
We also consider different initial subsidy levels, and keep $\varepsilon=\delta=\beta=$ $\mu=1, r=0.05, c=g=0, T=100$. Table 2 reports the results and shows there is a Weak Green Paradox for this set of parameter values. Keeping $\beta=\delta=\mu=1, r=0.05, c=0, T=100$, we can also consider different values for demand elasticity $\varepsilon$ of the manufactured good. These results are reported in Table 3. Finally, consider different values for supply elasticity of biofuels, $\mu$. We find that the Weak Green Paradox holds for a wide range of $\mu$, as reported in Table 4. As shown in this Table 4, with the exception of the first column where the supply elasticity of biofuels is smal, an increase in the subsidy rate will hasten the exhaustion of fossil fuels.

\section{Weak Green Paradox: cartel extraction}

What happens if oil is supplied by a cartel that behaves like a monopolist?

We assume that the monopolist takes the subsidy factor $z$ as a given constant. How does an increase in $z$ affect the extraction path?

As in Section 2, the residual demand function facing the oil producer is

$$
D_{f}(P ; z) \equiv D(P)-S_{B}(z P)
$$

The choke price for fossil fuels is $\bar{P}$, where $D(\bar{P})-S_{B}(z \bar{P})=0$, and $\bar{P}$ is decreasing in $z$, as we have stated in Fact 1 , see equation (4). We continue to assume that $\bar{P}$ is greater than the marginal cost of extraction, $c$.

Let $R_{t}$ denote the monopolist's stock of reserves at time $t$, so that $R_{0}=\bar{R}$ and $\dot{R}_{t}=-q_{t}$ where $q_{t}$ is the extraction rate. We assume that the monopolist's extraction matches the demand for fossil fuels:

$$
q_{t}=D_{f}\left(P_{t} ; z\right)
$$

The monopolist's optimization problem consists of choosing a time path of price $P_{t} \in[0, \bar{P}]$ and a terminal date $T$ to maximize the present value of its 
stream of discounted profit:

$$
\max _{T, P_{t}} \int_{0}^{T} e^{-r t}\left[\left(P_{t}-c\right) D_{f}\left(P_{t} ; z\right)\right] d t
$$

subject to the constraint

$$
\begin{gathered}
\dot{R}_{t}=-D_{f}\left(P_{t} ; z\right), \quad R_{0}=\bar{R} \\
R_{T} \geq 0
\end{gathered}
$$

Denote the elasticity of the demand for fossil fuels by $\theta_{t}\left(P_{t} ; z\right)$

$$
\theta_{t}\left(P_{t} ; z\right) \equiv-\frac{P_{t}}{D_{f}}\left(\frac{\partial D_{f}}{\partial P_{t}}\right)>0
$$

Assumption B: The elasticity of demand for fossil fuels is (i) greater than unity for sufficiently high $P$, and (ii) non-decreasing in $P$ :

$$
\frac{\partial \theta_{t}\left(P_{t} ; z\right)}{\partial P_{t}} \geq 0
$$

Let $\psi_{t}$ denote the current-value shadow price of the stock $R_{t}$ and let $H_{t}$ denote the current-value Hamiltonian. Then

$$
H_{t}=\left(P_{t}-c\right) D_{f}\left(P_{t} ; z\right)-\psi_{t} D_{f}\left(P_{t} ; z\right)
$$

The optimality conditions for the monopolist $\operatorname{are}^{6}$

$$
\begin{gathered}
P_{t}\left[1-\frac{1}{\theta_{t}}\right]-c-\psi_{t}=0 \Leftrightarrow \frac{\partial H_{t}}{\partial P_{t}}=0 \\
\dot{\psi}_{t}=r \psi_{t} \\
\psi_{T} \geq 0, \quad R_{T} \geq 0, \quad \psi_{T} R_{T}=0 \\
H_{T}=\left[P_{T}-c-\psi_{T}\right] D_{f}\left(P_{T} ; z\right)=0
\end{gathered}
$$

\footnotetext{
${ }^{6}$ As is well known, the monopolist always restricts supply so that $\theta_{t}>1$.
} 
One can show that conditions imply that $\psi_{T}=P_{T}-c>0, R_{T}=0, P_{T}=\bar{P}$, $D_{f}\left(P_{T} ; z\right)=0$, and $\theta_{T}=\infty$. In particular, we obtain the Hotelling Rule for the monopolist: the present value of marginal profit is the same for all $t \in[0, T]:$

$$
\left[\left(1-\frac{1}{\theta_{t}\left(P_{t} ; z\right)}\right) P_{t}-c\right]=(\bar{P}-c) e^{r(t-T)}
$$

Equation (22) implicitly defines the monopolist's optimal price $P_{t}$ as a function of $\bar{P}, z, t$ and $T$ :

$$
P_{t}=\phi^{m}(\bar{P}(z), t, T ; z)
$$

Note that the function $\phi^{m}$ in (23) is of the same nature as the function $\phi$ in (5) but they do not have the same functional form. Furthermore, the function $\phi^{m}$ depends on $z$ both via $\theta_{t}\left(P_{t} ; z\right)$ and via $\bar{P}$.

Example 1: Let $D(P)=a-b P$ and $S_{B}=g+z P$, where $a-g>0$. Then

$$
\theta=-\frac{P}{D_{f}}\left(\frac{\partial D_{f}}{\partial P}\right)=\frac{(b+z) P}{(a-g-(b+z) P)}
$$

Equation (22) reduces to

$$
P_{t}=\frac{1}{2}\left[(\bar{P}-c) e^{r(t-T)}+c+\frac{a-g}{b+z}\right] \equiv \phi^{m}(\bar{P}(z), t, T ; z)
$$

Returning to the general case, we make use of (23) to determine the monopolist's optimal exhaustion time $T$. It is the value of $T$ such that total accumulated extraction equals the initial reserve level $\bar{R}$ :

$$
\int_{0}^{T} D_{f}\left(\phi^{m}(\bar{P}(z), t, T ; z) ; z\right) d t=\bar{R}
$$

Lemma 2: An increase in the subsidy factor $z$ will bring the monopolist's resource-exhaustion date $T$ closer to the present if and only if the following integral is positive:

$$
\int_{0}^{T}\left[\frac{\partial D_{f}}{\partial P_{t}}\left(\frac{\partial \phi^{m}}{\partial \bar{P}} \frac{d \bar{P}}{d z}+\frac{\partial \phi^{m}}{\partial z}\right)+\frac{\partial D_{f}}{\partial z}\right] d t
$$


Proof: Let

$$
G^{m}(T, z, \bar{R}) \equiv \int_{0}^{T} D_{f}\left(\phi^{m}(\bar{P}(z), t, T) ; z\right) d t-\bar{R}
$$

The equilibrium condition that the stock of resources is exhausted at time $T$, i.e. $G(T, z, \bar{R})=0$, implicitly determines $T$ as a function of $z$. The derivative $d T / d z$ is given by

$$
\frac{d T}{d z}=-\frac{\frac{\partial G^{m}(T, z, \bar{R})}{\partial z}}{\frac{\partial G^{m}(T, z, \bar{R})}{\partial T}}
$$

where

$$
\frac{\partial G^{m}(T, z ; \bar{R})}{\partial T}=D_{f}\left(\phi^{m}(\bar{P}(z), T, T ; z) ; z\right)+\int_{0}^{T} \frac{\partial D_{f}}{\partial \phi^{m}} \frac{\partial \phi^{m}}{\partial T} d t>0
$$

and

$$
\frac{\partial G^{m}(T, z ; \bar{R})}{\partial z}=\int_{0}^{T}\left[\frac{\partial D_{f}}{\partial P_{t}}\left(\frac{\partial \phi^{m}}{\partial \bar{P}} \frac{d \bar{P}}{d z}+\frac{\partial \phi^{m}}{\partial z}\right)+\frac{\partial D_{f}}{\partial z}\right] d t
$$

In general, the sign of the right-hand side of equation (26) is uncertain. Thus, we consider a few special cases.

\subsection{Linear demand for fuels and linear supply of bio- fuels}

Let $D(P)=a-b P$ and $S_{B}=g+z P$ where $a-g>0$. Then

$$
\phi^{m}(\bar{P}(z), t, T ; z)=\frac{1}{2}\left[(\bar{P}-c) e^{r(t-T)}+c+\frac{a-g}{b+z}\right]
$$

and

$$
\begin{aligned}
& \frac{\partial D_{f}}{\partial P_{t}}\left(\frac{\partial \phi^{m}}{\partial \bar{P}} \frac{d \bar{P}}{d z}+\frac{\partial \phi^{m}}{\partial z}\right)+\frac{\partial D_{f}}{\partial z} \\
= & -\frac{c}{2}\left(1-e^{-r(T-t)}\right) \leq 0
\end{aligned}
$$

Proposition 3: Assume that the demand function for fuel and the supply function of biofuel are both linear. Then, under monopoly extraction, 
(i) if extraction costs are zero $(c=0)$, an increase in the biofuel subsidy factor $z$ will have no effect on the date of exhaustion of the resource stock $\bar{R}$;

(ii) if extraction costs are positive $(c>0)$, an increase in the biofuel subsidy factor $z$ will delay the date of exhaustion of the resource stock $\bar{R}$.

\subsection{Non-linear demand}

In this subsection, we consider the case where Assumption A is satisfied. In addition, assume $\mu=1$ and $g=0$. Then $D_{f}=(P+\delta)^{-\varepsilon}-\beta z P$, and the elasticity of demand for fossil fuels is

$$
\theta_{t}=\frac{\left[\varepsilon\left(P_{t}+\delta\right)^{-\varepsilon-1}+\beta z\right] P_{t}}{\left(P_{t}+\delta\right)^{-\varepsilon}-\beta z P_{t}}>0 \text { for } P_{t}<\bar{P}
$$

Note that if $\beta z>0$ and $\varepsilon \geq 1$ then $\theta_{t}>1$ because

$$
\theta_{t}>\frac{\varepsilon P_{t}}{P_{t}+\delta} \geq \varepsilon
$$

It can be verified that Assumption B is satisfied. Equation (22) becomes

$$
\left\{P_{t}-\frac{\left[\varepsilon\left(P_{t}+\delta\right)^{-\varepsilon-1}+\beta z\right] P_{t}}{\varepsilon\left(P_{t}+\delta\right)^{-\varepsilon-1}+\beta z}-c\right\}-(\bar{P}-c) e^{r(t-T)}=0
$$

or

$$
\left\{P_{t}-\frac{1}{\theta_{t}} P_{t}-c\right\}-(\bar{P}-c) e^{r(t-T)}=0
$$

Denote the right-hand side of equation (27) by $F\left(P_{t}, \bar{P}, t, T, z\right)$. Equation (27) yields the implicit function $P_{t}=\phi^{m}(\bar{P}(z), t, T ; z)$. Then

$$
\frac{\partial \phi^{m}}{\partial \bar{P}}=-\frac{\partial F / \partial \bar{P}}{\partial F / \partial P_{t}}=\frac{e^{r(t-T)}}{\left(1-\frac{1}{\theta_{t}}\right)+P_{t} \frac{d}{d P_{t}}\left(\frac{1}{\theta_{t}}\right)} \equiv \frac{e^{r(t-T)}}{\Omega_{t}}>0
$$

Furthermore,

$$
\frac{\partial \phi^{m}}{\partial z}=-\frac{\partial F / \partial z}{\partial F / \partial P_{t}}
$$


where

$$
\partial F / \partial z=-\frac{P_{t}}{\theta_{t}^{2}}\left(\frac{\partial \theta_{t}}{\partial z}\right)<0
$$

because

$$
\frac{\partial \theta_{t}}{\partial z}=\frac{\beta P_{t}}{\left(D_{f}\right)^{2}}\left[D_{f}+P_{t} \varepsilon(P+\delta)^{-\varepsilon-1}+z P_{t}\right]>0
$$

In other words, a higher biofuel subsidy increases the elasticity of demand for fossil fuels at any given price. Consequently,

$$
\frac{\partial \phi^{m}}{\partial z}=-\frac{\frac{\beta P_{t}^{2}}{\left(\theta_{t} D_{f}\right)^{2}}\left[D_{f}+P_{t} \varepsilon(P+\delta)^{-\varepsilon-1}+z P_{t}\right]}{\Omega_{t}}<0
$$

We can now compute the crucial expression in Lemma 2, condition (25):

$$
\begin{gathered}
\frac{\partial D_{f}}{\partial P_{t}}\left(\frac{\partial \phi^{m}}{\partial \bar{P}} \frac{d \bar{P}}{d z}+\frac{\partial \phi^{m}}{\partial z}\right)+\frac{\partial D_{f}}{\partial z} \\
=\frac{\varepsilon\left(P_{t}+\delta\right)^{-\varepsilon-1}+\beta z}{\Omega_{t}}\left(\frac{\bar{P} \beta e^{r(t-T)}}{\varepsilon(\bar{P}+\delta)^{-\varepsilon-1}+\beta z}+\frac{\beta P_{t}^{2}}{\left(\theta_{t} D_{f}\right)^{2}}\left[D_{f}+P_{t} \varepsilon(P+\delta)^{-\varepsilon-1}+z P_{t}\right]\right)-\beta P_{t}
\end{gathered}
$$

It appears that using this expression, the integral (25) can be positive or negative, depending on parameter values.

Proposition 4: Under Assumptions $A$ and B, the Weak Green Paradox is a possibility when fossil fuels are supplied by a cartel.

\section{A Two-country Model}

We now turn to the case where there are two countries with different energy policies. For simplicity we do not consider game theoretic or food policy issues (Bandyopadhyay et al. 2009). The "home country" is the U.S. The "foreign country" is China. There is no biofuel production in China. Assume that U.S. biofuels are not exported to China (e.g. because of high transport costs or other barriers to trade, or because the U.S. production subsidies are only given to domestically earmarked consumption). 
Let $P_{t}$ be the world price of fossil fuels. Assume that China's inverse demand function for fuels is

$$
P_{t}=A-\frac{1}{M^{c}} E_{t}^{c}
$$

where $E_{t}^{c}$ is the quantity demanded in China. Similarly, the US inverse demand function for fuels is

$$
P_{t}=A-\frac{1}{M^{u}} E_{t}^{u}
$$

Then $M^{c} / M^{u}$ is a measure of China's market size relative to the U.S.'s market size. By an appropriate choice of units, we can set $M^{u}=1$.

When the price is $P_{t}$, U.S. biofuel producers earn $z P_{t}$ for each unit they sell domestically, where $z$ is the subsidy factor. The biofuel supply function is $S_{B}=\beta(z P)^{\mu}$ and the U.S.'s residual demand for fossil fuels is $D_{f}^{u}=$ $A-P-\beta(z P)^{\mu}$. Let $\bar{P}_{u}$ be the solution of

$$
A-\bar{P}_{u}-\beta\left(z \bar{P}_{u}\right)^{\mu}=0
$$

Note that

$$
\frac{d \bar{P}_{u}}{d z}=-\frac{z^{\mu-1}\left(\bar{P}_{u}\right)^{\mu}}{\frac{1}{\beta \mu}+z^{\mu}\left(\bar{P}_{u}\right)^{\mu-1}}<0
$$

Given a positive constant subsidy factor $z>0$, the world equilibrium consists of two phases. In the first phase, fossil fuels are consumed in both the U.S. and China. This phase ends at an endogenously determined time $T^{u}$, when $P_{t}$ reaches the value $\bar{P}_{u}$. In the second phase, fossil fuels are only used in China, and U.S. energy demand is completely satisfied by biofuel production. The second phase ends at time $T^{w}$, when the world price of fossil fuels reaches the choke price $A$ and China's demand for fossil fuels becomes zero.

Our task is to find out how the subsidy rate $z$ influences the two critical times $T^{u}$ and $T^{w}$, and how it influences the equilibrium price path of fossil fuels, and hence the rate of emissions of $\mathrm{CO}_{2}$ at each point of time. 
Let $D^{w}(t)$ be the world (US and China) demand for fossil fuels during phase I, and $D^{c}(t)$ be China's demand for fossil fuels in phase II. Let $\bar{R}$ be the initial stock of fossil fuels. Equilibrium requires that the total use of fossil fuels equals its stock:

$$
\int_{0}^{T^{u}} D^{w}(t) d t+\int_{T^{u}}^{T^{w}} D^{c}(t) d t=\bar{R}
$$

We begin by evaluating the second integral on the left-hand side of (30). Assume zero extraction cost and perfect competition. Hotelling's Rule gives us,

$$
P_{t} e^{-r t}=P\left(T_{u}\right) e^{-r T^{u}}=P\left(T^{w}\right) e^{-r T^{w}}
$$

Given that $P\left(T^{w}\right)=A$ and $P\left(T_{u}\right)=\bar{P}_{u}$,

$$
T^{w}-T^{u}=\frac{1}{r}\left(\ln A-\ln \bar{P}_{u}(z)\right) \equiv J(z)
$$

This indicates that the length of Phase II is an increasing function of the subsidy factor $z$.

$$
\frac{d J}{d z}=-\frac{1}{r \bar{P}_{u}}\left(\frac{d \bar{P}_{u}}{d z}\right)>0
$$

China's oil consumption during Phase II is

$$
\begin{gathered}
\int_{T^{u}}^{T^{w}} D^{c}\left(P_{t}\right) d t=M^{c} \int_{T^{u}}^{T^{w}}\left(A-P_{t}\right) d t=M^{c} \int_{T^{u}}^{T^{w}}\left(A-A^{-r\left(T^{w}-t\right)}\right) d t \\
=A M^{c}\left\{T^{w}-T^{u}-\frac{1}{r}\left[1-e^{-r\left(T^{w}-T^{u}\right)}\right]\right\} \\
=A M^{c}\left\{J(z)-\frac{1}{r}\left[1-e^{-r J(z)}\right]\right\} \equiv K(z)
\end{gathered}
$$

It is easy to verify that $K(z)$ is an increasing function: the higher is the biofuel subsidy factor in the U.S., the greater is China's total consumption in Phase II.

$$
\frac{d K}{d z}=A M^{c}\left(1-e^{-r J(z)}\right) \frac{d J}{d z}>0
$$


Let us turn to Phase I, in which fossil demands are positive in both countries. The total accumulated consumption of fossil fuels in Phase I must equal $\bar{R}-K(z)$ :

$$
\int_{0}^{T^{u}}\left[D_{f}^{u}\left(P_{t}\right)+D^{c}\left(P_{t}\right)\right] d t=\bar{R}-K(z)
$$

where

$$
P_{t}=\bar{P}_{u} e^{-r\left(T^{u}-t\right)} \equiv \phi\left(\bar{P}_{u}(z), t, T^{u}\right)
$$

Define

$$
G\left(T^{u}, z, \bar{R}\right) \equiv \int_{0}^{T^{u}}\left[D_{f}^{u}(\phi, z)+D^{c}(\phi)\right] d t-\bar{R}+K(z)
$$

The effect of an increase in the subsidy factor $z$ on $T^{u}$ is given by

$$
\frac{d T^{u}}{d z}=-\frac{\partial G / \partial z}{\partial G / \partial T^{u}}
$$

where

$$
\partial G / \partial T^{u}=D^{c}\left(\bar{P}_{u}\right)+\int_{0}^{T^{u}}\left[\frac{\partial D_{f}^{u}}{\partial P_{t}}+\frac{\partial D^{c}}{\partial P_{t}}\right] \frac{\partial \phi}{\partial T^{u}} d t>0
$$

and

$$
\partial G / \partial z=\int_{0}^{T^{u}}\left[\left(\frac{\partial D_{f}^{u}}{\partial P_{t}}+\frac{\partial D^{c}}{\partial P_{t}}\right) \frac{\partial \phi}{\partial \bar{P}_{u}} \frac{d \bar{P}_{u}}{d z}+\frac{\partial D_{f}^{u}}{\partial z}\right] d t+\frac{d K}{d z}
$$

where, using Hotelling's Rule, the integrand can be simplified to

$$
z^{\mu-1} \mu \beta e^{r(t-T)}\left[\frac{1+M_{c}+\mu \beta z^{\mu}\left(P_{t}\right)^{\mu-1}}{1+\mu \beta z^{\mu}\left(\bar{P}_{u}\right)^{\mu-1}}-1\right]
$$

which is positive if $\mu \simeq 1$.

What about the effect of an increase in $z$ on $T^{w}$ ?

$$
\frac{d T^{w}}{d z}=\frac{d T^{u}}{d z}+\frac{d J}{d z}
$$

This expression is negative if and only if

$$
-\int_{0}^{T^{u}}\left[\left(\frac{\partial D_{f}^{u}}{\partial P_{t}}+\frac{\partial D^{c}}{\partial P_{t}}\right) \frac{\partial \phi}{\partial \bar{P}_{u}} \frac{d \bar{P}_{u}}{d z}+\frac{\partial D_{f}^{u}}{\partial z}\right] d t-\frac{d K}{d z}+\left(\partial G / \partial T^{u}\right) \frac{d J}{d z}<0
$$


i.e. iff

$-\int_{0}^{T^{u}}\left[\left(\frac{\partial D_{f}^{u}}{\partial P_{t}}+\frac{\partial D^{c}}{\partial P_{t}}\right) \frac{\partial \phi}{\partial \bar{P}_{u}} \frac{d \bar{P}_{u}}{d z}+\frac{\partial D_{f}^{u}}{\partial z}\right] d t-\left[\frac{d J}{d z}\right]\left[A M^{c}\left(1-e^{-r J(z)}\right)-\left(\partial G / \partial T^{u}\right)\right]<0$

So, if $\frac{d \bar{P}_{u}}{d z}$ is sufficiently large in absolute value, an increase in biofuel subsidy will bring the resource exhaustion date closer to the present.

Proposition 5: An increase in the subsidy factor z will lengthen Phase II and may shorten Phase I. The exhaustion date will be brought closer to the present if $\frac{d \bar{P}_{u}}{d z}$ is sufficiently large in absolute value.

Remark: From equation (29), higher values of $\beta \mu$ will be favourable to the Green Paradox.

\section{Weak Green Paradox with stock-dependent extraction costs}

We now turn to an investigation of the possibility of a Weak Green Paradox result in the case where extraction costs are stock-dependent. In what follows, we consider a model where extraction cost rises as the remaining stock falls. There are two possible scenarios. In the first scenario, the marginal cost of extracting the 'last drop of oil', although high, is still below the choke price for fossil fuels, and therefore all the fossil fuel stock will eventually be exhausted. In the second scenario, the last drop of oil is prohibitively expensive to extract, and therefore firms will abandon their deposits without exhausting them. ${ }^{7}$ We investigate the possibility of the Weak Green Paradox in both cases.

\footnotetext{
${ }^{7}$ Some authors have therefore modeled the "resource exhaustion" in the sense of an "economic abandonment" of the deposit after the profitable part has been exploited (see for example Karp, 1984, Rubio and Escriche 2001, Salo and Tahvonen, 2001, Chou and Long, 2009, Fujiwara and Long, 2009).
} 


\subsection{A model of stock-dependent extraction costs}

We assume that oil firms are perfectly competitive. They take the price path as given. Let $R_{0}=\bar{R}$ denote the initial stock of the representative firm, and $q_{t}$ denote its output at $t$. Let $R_{t}$ be the stock that remains at time $t$. Then $\dot{R}_{t}=-q_{t}$. We postulate that the total cost of extracting $q_{t}$ is linear in $q_{t}$ for given $R_{t}$ :

$$
\left[c_{0}+c_{1}\left(\bar{R}-R_{t}\right)\right] q_{t}, \quad c_{0} \geq 0, c_{1} \geq 0, R_{t} \in[0, \bar{R}], R_{0}=\bar{R} .
$$

Then $c_{0}+\left(\bar{R}-R_{t}\right) c_{1}$ is the marginal cost of extraction at time $t$. As the remaining stock $R_{t}$ falls, the marginal extraction cost rises. If $R_{t}=0$, the marginal extraction cost is $c_{0}+c_{1} \bar{R}$. Thus $c_{0}+c_{1} \bar{R}$ is the marginal cost of extracting the last drop of oil, and $c_{1}$ is the sensitivity of marginal cost to the remaining stock.

It is convenient to define a new state variable, $Y_{t}$, which represents accumulated extraction from date 0 to date $t$ :

$$
Y_{t} \equiv \bar{R}-R_{t}, \quad Y_{0}=0, \quad \dot{Y}_{t}=q_{t}
$$

Then the marginal extraction cost function may be written as $C\left(q_{t}, Y_{t}\right)=$ $c_{0}+c_{1} Y_{t}$.

As in the earlier sections, let the demand function for fuels be $E_{t}^{d}=D\left(P_{t}\right)$, $D^{\prime}<0$, where $E^{d}$ is the quantity of fuels demanded. Let the supply function for biofuels be $B_{t}=S_{B}\left(z P_{t}\right), S_{B}^{\prime}>0$. Then the demand for fossil fuels falls to zero at the "fossil fuel choke price" $\bar{P}$ defined by

$$
D(\bar{P})-S_{B}(z \bar{P})=0
$$

Since the representative oil firm's marginal cost is $c_{0}+c_{1} Y_{t}$, and $Y_{t} \leq \bar{R}$, we conclude that:

(i) if $c_{0}+c_{1} \bar{R}<\bar{P}(z)$ then the representative firm will eventually exhaust all its stock, 
(ii) if $c_{0}+c_{1} \bar{R}>\bar{P}(z)$, the representative firm will abandon its deposit when the reserve level falls to some postive level $R_{L}$ defined by

$$
\bar{c}-c_{1}\left(\bar{R}-R_{L}\right)=\bar{P}(z), R_{L}>0
$$

We will consider these two cases separately. Before doing so, let us make some clarification about the Hotelling Rule which we will use to explore the Weak Green Paradox.

\subsection{Hotelling Rule when extraction costs are stock- dependent}

What is the correct Hotelling Rule if the marginal extraction cost depends on the stock? The answer depends on the assumption one makes about the behavior of the firms. If firms do not "internalize" the added future cost caused by its current extraction, the present value of net price (price minus marginal extraction cost) must be the same at any pair of dates $\left(t, t^{\prime}\right)$

$$
\left[P_{t}-\left(c_{0}+c_{1} Y_{t}\right)\right] e^{-r t}=\left[P_{t^{\prime}}-\left(c_{0}+c_{1} Y_{t^{\prime}}\right)\right] e^{-r t^{\prime}}
$$

or

$$
P_{t}-\left(c_{0}+c_{1} Y_{t}\right)=\left[P_{t^{\prime}}-\left(c_{0}+c_{1} Y_{t^{\prime}}\right)\right] e^{-r\left(t^{\prime}-t\right)}
$$

Differentiating with respect to $t$ we get

$$
\dot{P}_{t}-c_{1} \dot{Y}_{t}=r\left[P_{t^{\prime}}-\left(c_{0}+c_{1} Y_{t^{\prime}}\right)\right] e^{-r\left(t^{\prime}-t\right)}
$$

Taking the limit as $t^{\prime} \rightarrow t$, we get the "non-internalized" Hotelling Rule ${ }^{8}$

$$
\dot{P}_{t}-c_{1} \dot{Y}_{t}=r\left[P_{t}-\left(c_{0}+c_{1} Y_{t}\right)\right]
$$

\footnotetext{
${ }^{8}$ Solow and Wan (1976) considered a macro-model of resource extraction with a continuum of heterogeneous firms, and assumed each firm produces only at a point of time. By construction, these firms do not internalize the added cost, since each firm's operating life is infinitessimally small. The authors obtained a kind of "non-internalized" evolution of price. For a discussion of Solow and Wan (1976), see Kemp and Long (2009).
} 
On the other hands, if firms internalize the added future cost caused by its current extraction, then the correct Hotelling Rule is the following "internalized Hotelling Rule"9

$$
\dot{P}_{t}=r\left[P_{t}-\left(c_{0}+c_{1} Y_{t}\right)\right]
$$

To prove that the rule (34) follows from optimizing behavior of far-sighted firms in the absence of externalities, consider the firm's optimization problem

$$
\max _{q_{t}, T} \int_{0}^{T} e^{-r t}\left[P_{t}-\left(c_{0}+c_{1} Y_{t}\right)\right] q_{t} d t
$$

subject to $\dot{Y}_{t}=q_{t}, Y_{0}=0$ and $Y_{T} \leq \bar{R}$. Let $\lambda_{t}$ be the co-state variable. The current-value Hamiltonian is

$$
H=P_{t} q_{t}-\left(c_{0}+c_{1} Y_{t}\right) q_{t}+\lambda_{t} q_{t}
$$

The necessary conditions include

$$
\begin{gathered}
P_{t}-\left(c_{0}+c_{1} Y_{t}\right)+\lambda_{t}=0 \\
\dot{\lambda}_{t}=r \lambda_{t}-\frac{\partial H_{t}}{\partial Y_{t}}=r \lambda_{t}+c_{1} q_{t}
\end{gathered}
$$

From these two equations, we obtain the "internalized Hotelling Rule", $\dot{P}_{t}=$ $r\left[P_{t}-\left(c_{0}+c_{1} Y_{t}\right)\right]$.

In what follows, we will use the internalized Hotelling Rule.

\subsection{Weak Green Paradox with stock-dependent extrac- tion costs and finite exhaustion date}

As we have stated above, if the marginal cost of extracting the last drop of oil, $c_{0}+c_{1} \bar{R}$, is lower than the fossil fuel choke price, $\bar{P}(z)$, then the entire stock $\bar{R}$ will be exhausted at some time $T$. In this case, the Weak Green Paradox is said to hold if a marginal increase in $z$ leads to an earlier exhaustion date.

\footnotetext{
${ }^{9}$ See Gaudet (2007) for a literature review of internalized Hotelling Rule.
} 
To determine the exhaustion date $T$, we must solve the following system of differential equations

$$
\begin{gathered}
\dot{P}_{t}=r\left[P_{t}-\left(c_{0}+c_{1} Y_{t}\right)\right] \\
\dot{Y}_{t}=D_{f}\left(P_{t} ; z\right)
\end{gathered}
$$

subject to three boundary conditions: $Y_{0}=0, Y_{T}=\bar{R}, P_{T}=\bar{P}(z)$. Once we have found $T$, we can investigate how $T$ responds to an increase in the biofuel subsidy.

\subsubsection{The linear demand case}

Suppose the demand function $D_{f}\left(P_{t} ; z\right)$ is linear. Let

$$
D_{f}(P ; z)=a-(b+\beta z) P, \quad a>0, b>0, \beta>0, z>0
$$

Then

$$
\bar{P}(z)=\frac{a}{b+\beta z}
$$

Assume $\frac{a}{b+\beta z}>c_{0}+c_{1} \bar{R}$ so that the whole stock $\bar{R}$ will be exhausted in finite time.

We must analyze the system

$$
\begin{gathered}
\dot{P}_{t}=r\left[P_{t}-\left(c_{0}+c_{1} Y_{t}\right)\right] \\
\dot{Y}_{t}=a-(b+\beta z) P
\end{gathered}
$$

subject to three boundary conditions: $Y_{0}=0, Y_{T}=\bar{R}, P_{T}=\bar{P}(z)$. The Appendix gives the solution.

In this case, we can show that the Weak Green Paradox does not hold. This is stated as Proposition 6 below. 
Proposition 6: If the demand function $D_{f}(P ; z)$ is linear in $P$, and the entire stock $\bar{R}$ is exhausted at some time $T$, then

(i) an increase in the subsidy factor $z$ will delay the exhaustion date,

(ii) higher sensitivity of extraction cost with respect to the remaining stock results in a later exhaustion date.

\section{Proof:}

From the assumption that $\frac{a}{b+\beta z}>c_{0}+c_{1} \bar{R}$, let us define

$$
\tilde{Y}(z) \equiv \frac{a}{c_{1}(b+\beta z)}-\frac{c_{0}}{c_{1}}>\bar{R}
$$

In the Appendix, we show that the exhaustion date $T$ is the unique positive solution of the following equation

$$
\frac{\left(\rho_{2}-\rho_{1}\right)}{\rho_{2} e^{-\rho_{1} T}-\rho_{1} e^{-\rho_{2} T}}=\left(\frac{\tilde{Y}(z)-\bar{R}}{\widetilde{Y}(z)}\right)
$$

where $\rho_{1}$ and $\rho_{2}$ are functions of $z$ :

$$
\begin{aligned}
& \rho_{2}=\frac{1}{2}\left(r+\sqrt{r^{2}+4 r c_{1}(b+\beta z)}\right)>0 \\
& \rho_{1}=\frac{1}{2}\left(r-\sqrt{r^{2}+4 r c_{1}(b+\beta z)}\right)<0
\end{aligned}
$$

Define

and

$$
F(T, z)=\frac{\left(\rho_{2}-\rho_{1}\right)}{\rho_{2} e^{-\rho_{1} T}-\rho_{1} e^{-\rho_{2} T}}
$$

$$
G(T, z) \equiv F(T, z)-\left(\frac{\widetilde{Y}(z)-\bar{R}}{\widetilde{Y}(z)}\right)
$$

To prove part (i), note that the effect on $T$ of an increase in the subsidy $z$ is

$$
\frac{d T}{d z}=-\frac{\frac{\partial G}{\partial z}}{\frac{\partial G}{\partial T}}
$$

We can show that

$$
\frac{\partial G}{\partial T}=-\frac{\rho_{1} \rho_{2}\left(\rho_{2}-\rho_{1}\right)^{2} e^{\rho_{2} T}}{\left\{\rho_{2} e^{\left(\rho_{2}-\rho_{1}\right) T}-\rho_{1}\right\}^{2}}\left[e^{\rho_{2} T}-e^{\left(2 \rho_{2}-\rho_{1}\right)}\right]<0
$$


and

$$
\frac{\partial G}{\partial z}=\frac{\partial F}{\partial z}-\bar{R}[\tilde{Y}(z)]^{-2} \frac{d \tilde{Y}}{d z}>0
$$

since $\frac{\partial F}{\partial z}>0$.

To prove part (ii), we use $\frac{d T}{d c_{1}}=-\left(\frac{\partial G}{\partial c_{1}}\right) /\left(\frac{\partial G}{\partial T}\right)$ and show that $\left(\frac{\partial G}{\partial c_{1}}\right)>$ 0.

As a numerical example, let $a=3, b=\beta=z=1$ and $\bar{R}=80$. We find the stock $\bar{R}$ will be exhausted in 370 years. If the subsidy factor is $z=1.1$, we find that $T$ increases to 410 years. In this special case, the Weak Green Paradox does not hold, at least in the long run.

\subsubsection{The non-linear demand case}

We conclude our results with the more general case of a non-linear demand and suppose that

$$
D_{f}(P, z)=(P+\delta)^{-\varepsilon}-\beta(z P)^{\mu}
$$

Thus $\bar{P}(z)$ is the solution of

$$
(P+\delta)^{-\varepsilon}-\beta(z P)^{\mu}=0
$$

The system to be analyzed is as follows:

$$
\begin{gathered}
\dot{P}_{t}=r\left[P_{t}-\left(c_{0}+c_{1} Y_{t}\right)\right] \\
\dot{Y}_{t}=(P+\delta)^{-\varepsilon}-\beta(z P)^{\mu}
\end{gathered}
$$

subject to three boundary conditions: $Y_{0}=0, Y_{T}=\bar{R}, P_{T}=\bar{P}(z)$. Unlike linear demand case, we cannot obtain an analytical solution.

Consider an example. Let $\varepsilon=\mu=\beta=\delta=1$. Then $\bar{P}$ is the solution of

$$
\frac{1}{(P+1)}-z P=0
$$


At $z=1$, the fossil fuel choke price is 0.618 . Assuming that $c_{0}=0.005$, $c_{1}=0.0001$ and $\bar{R}=80$, we can solve for the current oil price $P(0)=$ 0.017 , and the exhaustion date $T \simeq 106.9$ years. These cost and oil reserve parameters imply that the current extraction cost/price ratio is $29 \%$. Until the extraction date, costs in this case increases slightly from 0.005 to 0.013 , but the fuel price increases faster from 0.017 to 0.618 , and thus the relevant cost/price ratio at the exhaustion date is just $2 \%$.

For fossil fuel producers to abandon extraction before reserves are exhausted, the subsidy must satisfy:

$$
c_{0}+c_{1} \bar{R}=0.013>\bar{P}(z) \text { or } z>153.8
$$

Does a small increase in $z$ lead to an increase or a decrease in $T$ ? The answer depends on various parameters, particularly cost sensitivity or $c_{1}$. Our numerical simulations show that if extraction costs increase faster as the reserve depletes (a large value of $c_{1}$ ), then, starting from $z=1$, a small increase in the subsidy will make oil reserves last longer (a larger $T$ ). On the other hand, if $c_{1}$ is small enough, then an increase in the subsidy may lead to earlier exhaustion. We illustrate this in Table 5 where the subsidy $z$ is increased from1 to $1.2(\Delta z=0.2)$. Table 5 illustrates it is possible to find a large range of cases where fossil fuel reserves are exhausted faster, and the Weak Green Paradox holds.

The findings in Table 5 do not imply the Weak Green Paradox is a general result. Indeed, if condition (31) holds, we can show that with linear demand and a marginal extraction costs that increases linearly with accumulated extraction, and without technological change, fossil fuel deposits are abandoned before exhaustion and a subsidy for biofuels production results in a smaller overall consumption of fossil fuels. In that case, we say that the Weak Green Paradox does not hold in the long run. However, the long run is very long (abandonment takes place at time infinity). Thus, even when 
the Weak Green Paradox does not hold in the long run, our results indicate that it can plausibly hold in the short or medium term.

The time period overwhich the Weak Green Paradox holds is critically important. In terms of climate change and avoiding the severe impacts of climate change, what happens to cumulative emissions over the next 30 years interval is critical. It is this period of time that is likely to be the important period in terms of biofuels subsidies as we might reasonably assume that new, carbon neutral energy technologies will become more widespread beyond 30 years. Thus, in the time periods that matter we have real cause for concern that biofuel subsidies may actually encourage larger GHG emissions from fossil fuel combustion and increase the likelihood of the more severe impacts of climate change.

Another relevant issue is technological change that affects extraction costs and the net price path on non-renewables. Technological change would seem to be especially important in terms of stock-dependent extraction costs. Positive technological change should offset the effect of stock-dependent extraction, and may do so for a long time. The overall impact of technological change would depend on the relative changes of $z$ over time, on the extent to which technological changes affect the extraction costs and the cost of biofuel production, and the nature of stock dependent costs.

\section{Concluding Remarks}

We examine some possible cases under which there may be a Weak Green

Paradox lurking behind policies of biofuel subsidies whereby the supply-side response by fossil fuel producers more than offset any gains from substitution to biofuels. Whether the Weak Green Paradox holds or not depends on demand and supply elasticities, expected changes in subsidies, technological change in fossil fuel extraction and how extraction costs respond to changes 
in remaining reserves.

Our results suggest that a Weak Green Paradox from biofuel subsidies is a real possibility: policies designed to reduce GHG emissions may, perversely, hasten climate change. Further development of our models is necessary to take into account game-theoretic issues, the effects of technological change on extraction costs, the impacts of GHG atmospheric concentrations and the rates of decay, and the GHG reductions from direct biofuel-fossil fuel substitution. Nevertheless, our findings are sufficiently well developed to require, at the very least, that policy makers carefully evaluate the supplyside effects of biofuel subsidies on the extraction rate of fossil fuels by resource owners.

Acknowledgements: We thank Hassan Benchekroun, Kenji Fujiwara, Gerard Gaudet, John M. Hartwick and Jack Pezzey for helpful comments. This research is supported by the Social Sciences and Humanities Reseach Council of Canada, the Fonds québécois de la recherche sur la société et la culture and the Commonwealth Environmental Research Facility of the Australian Government.

\section{References}

[1] Bahel, E., G. Gaudet and W. Marrouch (2009), "The Economics of Oil, Biofuel and Food Commodities", Typescript, Université de Montréal.

[2] Bandyopadhyay, S., S. Bhaumik and H.J. Wall (2009), "Biofuel Subsidies: An Open-Economy Analysis". Discussion Paper No. 4584, The Instute for the Study of Labor (IZA).

[3] Chakravorty, U., M.-H. Hubert, and L. Nostbakken (2009), "Fuel versus Food", Working Paper No.2009-20, Department of Economics, University of Alberta.

[4] Chou, S. and N. V. Long (2009), "Optimal Tariffs on Exhaustible Resources in the Presence of Cartel Behavior," Asia-Pacific Journal of Accounting and Economics, 16(3): 239-254. 
[5] Food and Agriculture Organization of the United Nations (2008), "Highlevel Conference on World Food Security: The Challenges of Climate Change and Bioenergy", Rome, 3-5 June.

[6] Fujiwara, K. and N. V. Long (2009), "Optimal Tariff on Exhaustible Resourcs: A Leader-Follower Model" Working Paper, McGill University.

[7] Gaudet, G. (2007), "Natural Resource Economics under the Rule of Hotelling," Canadian Journal of Economics 40(4): 1033-1-59.

[8] Hill, J., E. Nelson,, D. Tilman, S. Polasky and D. Tiffany (2006), "Environmental, economic, and energic costs and benefitrs of biodiesel and ethanol biofuels", Proceedings of the National Academy of Sciences 103 (30): 11206-11210.

[9] Hoel, M. (2008), "Bush Meets Hotelling: Effects of Improved Renewable Energy Technology on Greenhouse Gas Emissions", CESifo Working Paper No. 2492.

[10] Karp, L. S. (1984), "Optimality and Consistency in a Differential Game with Non-Renewable Resources," Journal of Economic Dynamics and Control 8: 73-97.

[11] Kemp, M. C. and N. V. Long (2009), "Extracting Several Resource Deposits of Unknown Size: Optimal Order," German Economic Review 10: 401-421.

[12] Long, N. V. and H.-W. Sinn (1985), "Surprise Price Shift, Tax Changes and the Supply Behaviour of Resource Extracting Firms", Australian Economic Papers, 24(45): 278-289.

[13] Rubio, S. and L. Escriche (2001), "Strategic Pigouvian Taxation, Stock Externalities and Polluting Non-renewable Resources," Journal of Public Economics 79: 297-313.

[14] Salo, S. and O. Tavohnen (2001), "Oligopoly Equilibria in Nonrenewable Resource Markets," Journal of Economic Dynamics and Control 25: 671-702.

[15] Sinclair, P.J.N. (1992), "High Does Nothing and Rising is Worse: Carbon Taxes Should Keep Falling to Cut Harmful Emissions", Manchester School 60: 41-52.

[16] Sinn, H.-W. (2008a), "Public Policies Against Global Warming: A Supply-Side Approach", International Tax and Public Finance, 15(4):360-394. 
[17] Sinn, H.-W. (2008b), Das Grüne Paradoxon: Plädoyer für eine illusionsfreie Klimatpolitik, Econ Verlag, Berlin.

[18] Solow, R. M., and F.Y. Wan (1976), "Extraction Costs in the Theory of Exhaustible Resources," Bell Journal of Economics, Vol. 7, 359-370.

[19] Steenblik, R. (2007), "Biofuels - At What Cost? Government support for ethanol and biodiesel in selected OECD countris", Global Subsidies Initiative, Geneva.

[20] Ulph, A. and D. Ulph (1994), "The Optimal Time Path of a Carbon Tax", Oxford Economic Papers 46: 857-868. 


\section{APPENDIX}

\section{Exhaustion with stock-dependent cost and linear demand}

With the linear demand $D_{f}\left(P_{t} ; z\right)=a-(b+\beta z) P_{t}$, the fossil fuel choke price is $\bar{P}(z)=\frac{a}{b+\beta z}$. Assume that the marginal cost of extracting the last drop of oil is lower than the fossil fuel choke price:

$$
\bar{R}<\frac{a}{c_{1}(b+\beta z)}-\frac{c_{0}}{c_{1}} \equiv \widetilde{Y}(z)
$$

Consider the system

$$
\begin{gathered}
\dot{P}_{t}=r\left[P_{t}-\left(c_{0}+c_{1} Y_{t}\right)\right], \quad r>0, c_{0}>0, c_{1}>0 \\
\dot{Y}_{t}=D_{f}\left(P_{t} ; z\right)=a-(b+\beta z) P_{t}, \quad a>0, b>0, \beta>0, z>0
\end{gathered}
$$

subject to three boundary conditions: $Y_{0}=0, Y_{T}=\bar{R}, P_{T}=\bar{P}(z)$.

Write the system of differential equations in matrix form:

$$
\left[\begin{array}{l}
\dot{P} \\
\dot{R}
\end{array}\right]=\left[\begin{array}{ll}
a_{11} & a_{12} \\
a_{21} & a_{22}
\end{array}\right]\left[\begin{array}{l}
P \\
R
\end{array}\right]+\left[\begin{array}{l}
b_{1} \\
b_{2}
\end{array}\right]
$$

where $a_{11}=r, a_{12}=-r c_{1}, a_{21}=-(b+\beta z), a_{22}=0, b_{1}=-r c_{0}$ and $b_{2}=a$.In simpler notation,

$$
\dot{\mathbf{w}}=\mathbf{A} \mathbf{w}+\mathbf{b}
$$

where $\operatorname{det} \mathbf{A}=a_{11} a_{22}-a_{12} a_{21}=-r c_{1}(b+\beta z)<0$

$$
\mathbf{A}^{-1}=\frac{1}{-r c_{1}(b+\beta z)}\left[\begin{array}{cc}
0 & r c_{1} \\
b+\beta z & r
\end{array}\right]
$$

Define $\widetilde{\mathbf{w}}$ by

$$
\widetilde{\mathbf{w}}=-\mathbf{A}^{-1} \mathbf{b}
$$

Then

$$
\widetilde{\mathbf{w}}=\left[\begin{array}{c}
\frac{a}{b+\beta z} \\
\frac{a}{(b+\beta z) c_{1}}-\frac{c_{0}}{c_{1}}
\end{array}\right] \equiv\left[\begin{array}{c}
\widetilde{w}_{1} \\
\widetilde{w}_{2}
\end{array}\right]
$$

Now let us define $\mathbf{x}$ by

$$
\mathbf{x} \equiv \mathbf{w}-\widetilde{\mathbf{w}}
$$


Let $\rho_{1}<0$ and $\rho_{2}>0$ be the characteristic roots,

$$
\begin{aligned}
\rho_{1,2} & =\frac{a_{11}+a_{22} \pm \sqrt{\left(a_{11}+a_{22}\right)^{2}-4\left(a_{11} a_{22}-a_{12} a_{21}\right)}}{2} \\
& =\frac{1}{2}(r \pm \sqrt{\Delta}) \text { where } \Delta \equiv r^{2}+4 r c_{1}(b+\beta z)
\end{aligned}
$$

Then the general solution is

$$
\left[\begin{array}{l}
x_{1}(t) \\
x_{2}(t)
\end{array}\right]=\left[\begin{array}{c}
h_{1} \\
-\left(a_{12}\right)^{-1}\left(a_{11}-\rho_{1}\right) h_{1}
\end{array}\right] \exp \left(\rho_{1} t\right)+\left[\begin{array}{c}
h_{2} \\
-\left(a_{12}\right)^{-1}\left(a_{11}-\rho_{2}\right) h_{2}
\end{array}\right] \exp \left(\rho_{2} t\right)
$$

where $h_{1}$ and $h_{2}$ are constants (to be determined using boundary conditions).

Define

$$
\begin{aligned}
& v_{1} \equiv-\left(a_{12}\right)^{-1}\left(a_{11}-\rho_{1}\right)=\frac{\rho_{1}-r}{-r c_{1}} \\
& v_{2} \equiv-\left(a_{12}\right)^{-1}\left(a_{11}-\rho_{2}\right)=\frac{\rho_{2}-r}{-r c_{1}}
\end{aligned}
$$

Setting $t=T$ in the matrix equation (35), and noting that have $x_{1}(T)=$ $P_{T}-\widetilde{w}_{1}=0$ and $x_{2}(T)=Y_{T}-\widetilde{w}_{2}=\bar{R}-\widetilde{w}_{2} \equiv \bar{R}-\widetilde{Y}(z)$, we get two equations:

$$
\begin{gathered}
0=h_{1} \exp \left(\rho_{1} T\right)+h_{2} \exp \left(\rho_{2} T\right) \\
\bar{R}-\widetilde{Y}(z)=v_{1} h_{1} \exp \left(\rho_{1} T\right)+v_{2} h_{2} \exp \left(\rho_{2} T\right)
\end{gathered}
$$

Equation (38) gives

$$
h_{1}=-h_{2} \exp \left[\left(\rho_{2}-\rho_{1}\right) T\right]
$$

Substituting into equation (39) to get

$$
\bar{R}-\tilde{Y}(z)=-v_{1} h_{2} \exp \left(\rho_{2} T\right)+v_{2} h_{2} \exp \left(\rho_{2} T\right)
$$

Therefore

$$
h_{2}=\frac{\bar{R}-\tilde{Y}(z)}{\left(v_{2}-v_{1}\right) \exp \left(\rho_{2} T\right)}
$$

Setting $t=0$ in the matrix equation (35), we get two equations

$$
\begin{gathered}
P_{0}-\bar{P}(z)=h_{1}+h_{2} \\
Y_{0}-\tilde{Y}(z)=v_{1} h_{1}+v_{2} h_{2}
\end{gathered}
$$


Since $Y_{0}=0$, substituting (40) and (41) into (43) we get

$$
-\tilde{Y}(z)=\frac{\bar{R}-\tilde{Y}(z)}{\left(v_{2}-v_{1}\right) \exp \left(\rho_{2} T\right)}\left[v_{2}-v_{1} \exp \left[\left(\rho_{2}-\rho_{1}\right) T\right]\right]
$$

or

$$
\frac{\left(v_{2}-v_{1}\right) \exp \left(\rho_{2} T\right)}{v_{2}-v_{1} \exp \left[\left(\rho_{2}-\rho_{1}\right) T\right]}=\frac{\widetilde{Y}(z)-\bar{R}}{\widetilde{Y}(z)}
$$

Now, using (36), (37) and (44)

$$
\frac{\left(\rho_{2}-\rho_{1}\right) \exp \left(\rho_{2} T\right)}{-\rho_{1}+\rho_{2} \exp \left[\left(\rho_{2}-\rho_{1}\right) T\right]}=\frac{\widetilde{Y}(z)-\bar{R}}{\widetilde{Y}(z)}
$$

Let

$$
\phi(T, z) \equiv \frac{\left(\rho_{2}-\rho_{1}\right)}{-\rho_{1} \exp \left[-\rho_{2} T\right]+\rho_{2} \exp \left[-\rho_{1} T\right]}
$$

The function $\phi(T, z)$ has the following properties: $\phi(0, z)=1, \partial \phi(T, z) / \partial T<$ 0 for all $T>0$, and

$$
\lim _{T \rightarrow \infty} \phi(T, z)=0
$$

It follows that the equation

$$
\phi(T, z)=\frac{\widetilde{Y}(z)-\bar{R}}{\widetilde{Y}(z)}
$$

has a unique solution $T>0$ (which depends on $z$ ).

Numerical examples Then

Suppose $\bar{R}=80, r=0.05, a=3, b=\beta=z=1, c_{0}=1$.Let $c_{1}=0.001$.

$$
\begin{gathered}
\tilde{Y}(z)=\frac{a}{(b+\beta z) c_{1}}-\frac{c_{0}}{c_{1}}=\frac{1}{c_{1}}\left(\frac{a}{b+\beta z}-c_{0}\right)=\frac{0.5}{c_{1}}=500 \\
\rho_{1}=-4.950975 \times 10^{-4} \\
\rho_{2}=5.0495098 \times 10^{-2}
\end{gathered}
$$

The equation

$$
\frac{\left(\rho_{2}-\rho_{1}\right)}{-\rho_{1} \exp \left(-\rho_{2} T\right)+\rho_{2} \exp \left(-\rho_{1} T\right)}=\frac{\widetilde{Y}(z)-\bar{R}}{\widetilde{Y}(z)}=0.84
$$


yields the unique solution $T=370$.

Now let $z$ increase to 1.1 . Then $T$ increases from 370 years to 410 years. If $c_{1}$ is higher, $c_{1}=0.002$, while $z=1$ and $\bar{R}=80$. It will take 394 years to exhaust $\bar{R}$.

Now let $z$ increase to 1.1 . Then $T$ increases from 394 years to 475 years. 


\begin{tabular}{|c|c|c|c|c|c|}
\hline$T$ & 50 & 75 & $\mathbf{1 0 0}$ & 150 & 200 \\
\hline$\frac{d T}{d z}$ & -1.75 & -2.04 & $\mathbf{- 2 . 0 9}$ & -2.110 & -2.113 \\
\hline
\end{tabular}

Table 1: Effect of a Biofuel Subsidy on Exhaustion Date for Different Fossil Fuel Reserve Sizes

\begin{tabular}{|c|c|c|c|c|c|}
\hline$z$ & 0.5 & 0.75 & $\mathbf{1}$ & 1.5 & 2 \\
\hline$\frac{d T}{d z}$ & -6.6 & -3.43 & $\mathbf{- 2 . 0 9}$ & -0.99 & -0.56 \\
\hline
\end{tabular}

Table 2: Effect of a Biofuel Subsidy on Exhaustion Date for Different Initial Subsidy Levels

\begin{tabular}{|c|c|c|c|c|c|}
\hline$\varepsilon$ & 0.1 & 0.5 & $\mathbf{1}$ & 2 & 3 \\
\hline$\frac{d T}{d z}$ & -0.35 & -1.34 & $\mathbf{- 2 . 0 9}$ & -2.89 & -3.32 \\
\hline
\end{tabular}

Table 3: Effect of a Biofuel Subsidy on Exhaustion Date for Different Demand Elasticities of the Manufactured Good

\begin{tabular}{|c|c|c|c|c|c|}
\hline$\mu$ & 0.5 & 0.75 & $\mathbf{1}$ & 1.5 & 2 \\
\hline$\frac{d T}{d z}$ & $\mathbf{1 . 4 5}$ & -2.07 & $\mathbf{- 2 . 0 9}$ & -3.88 & -3.75 \\
\hline
\end{tabular}

Table 4: Effect of a Biofuel Subsidy on Exhaustion Date for Different Supply Elasticities of Biofuel

\begin{tabular}{|l|l|l|l|l|l|}
\hline $\begin{array}{l}\text { Cost sensitiv- } \\
\text { ity parameter }\end{array}$ & $\begin{array}{l}\text { Marginal ex- } \\
\text { traction cost } \\
\text { of the 'last } \\
\text { drop' }\end{array}$ & $\begin{array}{l}\text { Choke fuel when } \\
\text { of fel } 1.2 / \mathrm{z}=1\end{array}$ & $\Delta T$ & $\Delta T / \Delta z$ & $\begin{array}{l}\text { Paradox/ No } \\
\text { Paradox }\end{array}$ \\
\hline 0 & 0.005 & $0.54 / 0.618$ & -0.270 & -1.35 & Paradox \\
\hline 0.0001 & 0.013 & $0.54 / 0.618$ & -0.176 & -0.88 & Paradox \\
\hline 0.0002 & 0.021 & $0.54 / 0.618$ & -0.077 & -0.39 & Paradox \\
\hline 0.0003 & 0.029 & $0.54 / 0.618$ & 0.025 & +0.13 & No Paradox \\
\hline 0.0005 & 0.045 & $0.54 / 0.618$ & 0.244 & +1.22 & No Paradox \\
\hline
\end{tabular}

Table 5: Parameter Values for the Weak Green Paradox 


\section{CESifo Working Paper Series}

for full list see www.cesifo-group.org/wp

(address: Poschingerstr. 5, 81679 Munich, Germany, office@cesifo.de)

2897 Michael McBride and Stergios Skaperdas, Conflict, Settlement, and the Shadow of the Future, December 2009

2898 Ben J. Heijdra and Laurie S. M. Reijnders, Economic Growth and Longevity Risk with Adverse Selection, December 2009

2899 Johannes Becker, Taxation of Foreign Profits with Heterogeneous Multinational Firms, December 2009

2900 Douglas Gale and Piero Gottardi, Illiquidity and Under-Valuation of Firms, December 2009

2901 Donatella Gatti, Christophe Rault and Anne-Gaël Vaubourg, Unemployment and Finance: How do Financial and Labour Market Factors Interact?, December 2009

2902 Arno Riedl, Behavioral and Experimental Economics Can Inform Public Policy: Some Thoughts, December 2009

2903 Wilhelm K. Kohler and Marcel Smolka, Global Sourcing Decisions and Firm Productivity: Evidence from Spain, December 2009

2904 Marcel Gérard and Fernando M. M. Ruiz, Corporate Taxation and the Impact of Governance, Political and Economic Factors, December 2009

2905 Mikael Priks, The Effect of Surveillance Cameras on Crime: Evidence from the Stockholm Subway, December 2009

2906 Xavier Vives, Asset Auctions, Information, and Liquidity, January 2010

2907 Edwin van der Werf, Unilateral Climate Policy, Asymmetric Backstop Adoption, and Carbon Leakage in a Two-Region Hotelling Model, January 2010

2908 Margarita Katsimi and Vassilis Sarantides, Do Elections Affect the Composition of Fiscal Policy?, January 2010

2909 Rolf Golombek, Mads Greaker and Michael Hoel, Climate Policy without Commitment, January 2010

2910 Sascha O. Becker and Ludger Woessmann, The Effect of Protestantism on Education before the Industrialization: Evidence from 1816 Prussia, January 2010

2911 Michael Berlemann, Marco Oestmann and Marcel Thum, Demographic Change and Bank Profitability. Empirical Evidence from German Savings Banks, January 2010 
2912 Øystein Foros, Hans Jarle Kind and Greg Shaffer, Mergers and Partial Ownership, January 2010

2913 Sean Holly, M. Hashem Pesaran and Takashi Yamagata, Spatial and Temporal Diffusion of House Prices in the UK, January 2010

2914 Christian Keuschnigg and Evelyn Ribi, Profit Taxation and Finance Constraints, January 2010

2915 Hendrik Vrijburg and Ruud A. de Mooij, Enhanced Cooperation in an Asymmetric Model of Tax Competition, January 2010

2916 Volker Meier and Martin Werding, Ageing and the Welfare State: Securing Sustainability, January 2010

2917 Thushyanthan Baskaran and Zohal Hessami, Globalization, Redistribution, and the Composition of Public Education Expenditures, January 2010

2918 Angel de la Fuente, Testing, not Modelling, the Impact of Cohesion Support: A Theoretical Framework and some Preliminary Results for the Spanish Regions, January 2010

2919 Bruno S. Frey and Paolo Pamini, World Heritage: Where Are We? An Empirical Analysis, January 2010

2920 Susanne Ek and Bertil Holmlund, Family Job Search, Wage Bargaining, and Optimal Unemployment Insurance, January 2010

2921 Mariagiovanna Baccara, Allan Collard-Wexler, Leonardo Felli and Leeat Yariv, Gender and Racial Biases: Evidence from Child Adoption, January 2010

2922 Kurt R. Brekke, Roberto Cellini, Luigi Siciliani and Odd Rune Straume, Competition and Quality in Regulated Markets with Sluggish Demand, January 2010

2923 Stefan Bauernschuster, Oliver Falck and Niels Große, Can Competition Spoil Reciprocity? - A Laboratory Experiment, January 2010

2924 Jerome L. Stein, A Critique of the Literature on the US Financial Debt Crisis, January 2010

2925 Erkki Koskela and Jan König, Profit Sharing, Wage Formation and Flexible Outsourcing under Labor Market Imperfection, January 2010

2926 Gabriella Legrenzi and Costas Milas, Spend-and-Tax Adjustments and the Sustainability of the Government’s Intertemporal Budget Constraint, January 2010

2927 Piero Gottardi, Jean Marc Tallon and Paolo Ghirardato, Flexible Contracts, January 2010 
2928 Gebhard Kirchgässner and Jürgen Wolters, The Role of Monetary Aggregates in the Policy Analysis of the Swiss National Bank, January 2010

2929 J. Trent Alexander, Michael Davern and Betsey Stevenson, Inaccurate Age and Sex Data in the Census PUMS Files: Evidence and Implications, January 2010

2930 Stefan Krasa and Mattias K. Polborn, Competition between Specialized Candidates, January 2010

2931 Yin-Wong Cheung and Xingwang Qian, Capital Flight: China’s Experience, January 2010

2932 Thomas Hemmelgarn and Gaetan Nicodeme, The 2008 Financial Crisis and Taxation Policy, January 2010

2933 Marco Faravelli, Oliver Kirchkamp and Helmut Rainer, Social Welfare versus Inequality Concerns in an Incomplete Contract Experiment, January 2010

2934 Mohamed El Hedi Arouri and Christophe Rault, Oil Prices and Stock Markets: What Drives what in the Gulf Corporation Council Countries?, January 2010

2935 Wolfgang Lechthaler, Christian Merkl and Dennis J. Snower, Monetary Persistence and the Labor Market: A New Perspective, January 2010

2936 Klaus Abberger and Wolfgang Nierhaus, Markov-Switching and the Ifo Business Climate: The Ifo Business Cycle Traffic Lights, January 2010

2937 Mark Armstrong and Steffen Huck, Behavioral Economics as Applied to Firms: A Primer, February 2010

2938 Guglielmo Maria Caporale and Alessandro Girardi, Price Formation on the EuroMTS Platform, February 2010

2939 Hans Gersbach, Democratic Provision of Divisible Public Goods, February 2010

2940 Adam Isen and Betsey Stevenson, Women’s Education and Family Behavior: Trends in Marriage, Divorce and Fertility, February 2010

2941 Peter Debaere, Holger Görg and Horst Raff, Greasing the Wheels of International Commerce: How Services Facilitate Firms’ International Sourcing, February 2010

2942 Emanuele Forlani, Competition in the Service Sector and the Performances of Manufacturing Firms: Does Liberalization Matter?, February 2010

2943 James M. Malcomson, Do Managers with Limited Liability Take More Risky Decisions? An Information Acquisition Model, February 2010

2944 Florian Englmaier and Steve Leider, Gift Exchange in the Lab - It is not (only) how much you give ..., February 2010 
2945 Andrea Bassanini and Giorgio Brunello, Barriers to Entry, Deregulation and Workplace Training: A Theoretical Model with Evidence from Europe, February 2010

2946 Jan-Emmanuel De Neve, James H. Fowler and Bruno S. Frey, Genes, Economics, and Happiness, February 2010

2947 Camille Cornand and Frank Heinemann, Measuring Agents' Reaction to Private and Public Information in Games with Strategic Complementarities, February 2010

2948 Roel Beetsma and Massimo Giuliodori, Discretionary Fiscal Policy: Review and Estimates for the EU, February 2010

2949 Agnieszka Markiewicz, Monetary Policy, Model Uncertainty and Exchange Rate Volatility, February 2010

2950 Hans Dewachter and Leonardo Iania, An Extended Macro-Finance Model with Financial Factors, February 2010

2951 Helmuth Cremer, Philippe De Donder and Pierre Pestieau, Education and Social Mobility, February 2010

2952 Zuzana Brixiová and Balázs Égert, Modeling Institutions, Start-Ups and Productivity during Transition, February 2010

2953 Roland Strausz, The Political Economy of Regulatory Risk, February 2010

2954 Sanjay Jain, Sumon Majumdar and Sharun W. Mukand, Workers without Borders? Culture, Migration and the Political Limits to Globalization, February 2010

2955 Andreas Irmen, Steady-State Growth and the Elasticity of Substitution, February 2010

2956 Bengt-Arne Wickström, The Optimal Babel - An Economic Framework for the Analysis of Dynamic Language Rights, February 2010

2957 Stefan Bauernschuster and Helmut Rainer, From Politics to the Family: How Sex-Role Attitudes Keep on Diverging in Reunified Germany, February 2010

2958 Patricia Funk and Christina Gathmann, How do Electoral Systems Affect Fiscal Policy? Evidence from State and Local Governments, 1890 to 2005, February 2010

2959 Betsey Stevenson, Beyond the Classroom: Using Title IX to Measure the Return to High School Sports, February 2010

2960 R. Quentin Grafton, Tom Kompas and Ngo Van Long, Biofuels Subsidies and the Green Paradox, February 2010 